\title{
Irrigação de salvação e cobertura do solo no rendimento de gravioleira 'morada' em safras consecutivas
}

\author{
Salvation of irrigation and soil coverage on yield soursop \\ 'morada' in consecutive crops
}

'Departamento de Solos e Engenharia Rural, Universidade Federal da Paraíba (UFPB), campus II, Rodovia PB 079, Km 12, CEP 58.397-000, Areia, PB, Brasil

${ }^{2}$ Centro de Ciências Humanas, Sociais e Agrărias, Universidade Federal da Paraība (UFPB), Bananeiras, PB, Brasil ${ }^{3}$ Instituto Federal de Educação Ciência e Tecnologia (IF Sertão), Petrolina, PE, Brasil

*autor correspondente \almeida_dacio@hotmail.com
RESUMO: A gravioleira tem se destacado por apresentar promissor potencial de comercialização no mercado interno, com perspectivas para exportação. Neste sentido o experimento foi executado no município de Remígio, Paraíba, entre junho/2008 e dezembro/2010, onde avaliaram os efeitos da ausência e presença da irrigação e da cobertura do solo com restos de cultura no comportamento produtivo da gravioleira 'Morada', estabelecida em 2001. Os tratamentos foram arranjados em blocos ao acaso, com três repetições e três plantas por parcela, utilizando-se o fatorial $2 \times 2 \times 2$, referente às plantas não irrigadas e sob irrigação com uma lâmina semanal de $17,2 \mathrm{~mm}$. planta $^{-1}$, no solo sem e com cobertura morta com espessura de $5 \mathrm{~cm}$, nas safras de 2008/2009 e 2009/2010, respectivamente. A cobertura morta do solo elevou o número e a massa média de frutos colhidos, a produção por planta e a produtividade da gravioleira, mas em menor proporção que a irrigação de salvação em ambas as safras. Destacando valores expressivos atingidos pelas plantas irrigadas e com adição de cobertura morta, onde a produção por planta chegou a $194,2 \mathrm{~kg}$ planta $^{-1}$ e a produtividade a $53,4 \mathrm{t} \mathrm{ha}^{-1}$.

PALAVRA CHAVE: Annona muricata L., comportamento produtivo, manejo de água.
ABSTRACT: Soursop has become known for presenting great marketing potential in the domestic market with prospects for export. The experiment was carried out in Remígio, Paraiba, Brazil, during the period of June/2008 to December/2010 in order to evaluate the effects of irrigation and soil mulching on productive behavior in soursop plants variety 'Morada', planted in year 2001. Treatments were distributed in randomized blocs with three repetition and three plant per plot using the factorial design $2 \times 2 \times 2$ referring the plants no irrigation and irrigated weekly with $17.2 \mathrm{~mm}^{\text {plant }^{-1}}$ in soil without and with mulching with layer of $5 \mathrm{~cm}$ during the harvest of 2008/2009 and 2009/2010. The soil mulching increase the number and the fruit weight, the plant production and productivity of soursop plants, but loss proportion that the plants irrigation in both yield. Highlighting significant amounts affected by irrigated plants and adding mulch, where production per plant reached $194.2 \mathrm{~kg} \mathrm{plant}^{-1}$ and productivity to $53.4 \mathrm{tha}^{-1}$.

KEYWORDS: Annona muricata L., productive behavior, water management. 


\section{Introdução}

A procura por frutos de graviola no mercado nacional e internacional é justificada pelo seu aroma e sabor agradáveis, valor nutritivo e medicinal (PAREEK et al., 2011). Esses atributos conferem potencial de comercialização da polpa, tanto para o consumo ao natural, na forma de suco, como para o processamento da polpa, na forma de sorvetes, doces, licores e outros produtos (SACRAMENTO et al., 2003; GARCIA-SOTO et al., 2012).

Dentre as gravioleiras exploradas no Brasil, a cultivar 'Morada' tem se destacado pela fácil adaptação aos mais diversos tipos de solo e por ser uma planta capaz de produzir acima de $40 \mathrm{~kg}$ de polpa por ano (SILVA; FARNEZI, 2009). Além disso, tem a vantagem de o fruto ser grande, com comprimento em torno de $25 \mathrm{~cm}$ e diâmetro de $12 \mathrm{~cm}$, o que se reflete em rendimento acima de $30 \mathrm{~kg}$ de frutos por planta, a polpa por ser mais clara que as de outras variedades e a casca por ser mais espessa, o que dificulta o ataque da broca do fruto. Entretanto, o rendimento por área, em geral, é baixo com produtividades inferiores a $9.000 \mathrm{~kg} \mathrm{ha}^{-1}$ ano, mesmo nos plantios com maiores densidades e conforme Ferreira, Rodrigues e Gomes Filho (2010), um dos fatores limitantes para a baixa produção das anonáceas é a carência de informações hídricas, como a evapotranspiração da cultura, sendo a água aplicada de forma quase sempre insuficiente ou de forma indevida no período de estiagem.

No que se refere à importância da irrigação às frutíferas, em geral, nas regiões semiáridas, a limitação hídrica pela carência de pluviosidade ou irregularidade das chuvas também pode comprometer a viabilidade do cultivo de gravioleiras (FONTENELE et al., 2013). Nessas áreas, as altas temperaturas do ar elevam a temperatura do solo e provocam perdas de água do ambiente radicular das plantas, com reflexos negativos na produção. Uma das tentativas para mitigar o problema é o uso de cobertura morta, visando diminuir a intensidade evaporativa na área de projeção da copa das plantas, mantendo o solo mais úmido e menos aquecido (TEÓFILO et al., 2012; LIMA
NETO et al., 2013; FREIRE et al., 2014), contribuindo para maiores índices de produção das culturas em geral.

Ao considerar a exigência hídrica da gravioleira adulta em produção, da ordem de $130 \mathrm{~L} \mathrm{dia}^{-1}$ no período de maior demanda evopatranspirativa (FONTENELE et al., 2013), nas áreas com atual restrição de manancial hídrico, baixa pluviosidade com irregularidades das chuvas, a irrigação de salvação, que é considerada uma lâmina inferior à exigida pela planta, pode contribuir para a produção da cultura durante o período de estiagem. Nessa situação, a irrigação de salvação, apesar de inferior, deve ser aplicada na área de projeção da copa das plantas sob cobertura morta, não como forma de garantir a elevação dos níveis de produtividade, mas de minimizar a variação das perdas de produção.

Pelo exposto, o trabalho teve como objetivo avaliar os efeitos da ausência e presença da irrigação no solo, sem e com cobertura morta com restos de cultura, nos componentes da produção da gravioleira 'Morada', nas safras consecutivas de 2008/2009 e 2009/2010.

\section{Material e Métodos}

$\mathrm{O}$ experimento foi realizado no município de Remígio, PB, localizado nas coordenadas geográficas $6^{\circ} 53^{\prime} 00^{\prime}$ 'S, $36^{\circ} 02^{\prime} 00^{\prime \prime} \mathrm{W}$ e a $470 \mathrm{~m}$ acima do nível do mar, entre os anos de 2008 e 2010. As plantas de graviola cv. 'Morada' (Annona muricata L.) foram implantadas em 2001, no espaçamento $6 \mathrm{~m} \times 6 \mathrm{~m}$. Os valores de pluviosidade, temperatura e umidade relativa do ar do local do experimento, nos anos de 2008, 2009 e 2010, estão na Tabela 1.

O delineamento experimental foi em blocos casualizados, com três repetições, sendo as parcelas constituídas por cinco plantas e avaliadas as três plantas centrais, adotando-se o arranjo fatorial $2 \times 2$, com amostras repetidas no tempo (duas safras), referente ao solo sem e com irrigação semanalmente $\left(0,0\right.$ e $\left.17,2 \mathrm{~mm}_{\text {planta }}{ }^{-1}\right)$, sem e com cobertura morta com restos de cultura, e duas safras consecutivas referentes a 2008/2009

Tabela 1. Valores de pluviosidade (P), temperatura (T) e umidade relativa do ar (UR), nos anos de 2008,2009 e 2010 , Remígio - PB.

\begin{tabular}{|c|c|c|c|c|c|c|c|c|c|}
\hline \multirow{2}{*}{ Meses } & \multicolumn{3}{|c|}{2008} & \multicolumn{3}{|c|}{2009} & \multicolumn{3}{|c|}{2010} \\
\hline & P mm & $\mathrm{T}^{\circ} \mathrm{C}$ & UR \% & P mm & $\mathrm{T}^{\circ} \mathrm{C}$ & UR \% & P mm & $\mathrm{T}^{\circ} \mathrm{C}$ & UR \% \\
\hline Janeiro & 21 & 26,0 & 60 & 35 & 26,3 & 64 & 10 & 26,7 & 59 \\
\hline Fevereiro & 6 & 27,1 & 59 & 29 & 27,0 & 62 & 8 & 24,9 & 45 \\
\hline Março & 154 & 26,3 & 77 & 126 & 26,1 & 79 & 58 & 24,9 & 68 \\
\hline Abril & 106 & 23,4 & 83 & 269 & 24,8 & 89 & 153 & 24,8 & 70 \\
\hline Maio & 102 & 22,3 & 87 & 111 & 25,4 & 85 & 41 & 24,2 & 76 \\
\hline Junho & 165 & 21,2 & 89 & 147 & 22,7 & 88 & 190 & 22,4 & 80 \\
\hline Julho & 85 & 22,2 & 78 & 239 & 22,1 & 92 & 96 & 22,1 & 82 \\
\hline Agosto & 124 & 22,3 & 81 & 113 & 22,8 & 82 & 56 & 21,5 & 86 \\
\hline Setembro & 37 & 24,2 & 64 & 15 & 24,3 & 78 & 46 & 24,8 & 78 \\
\hline Outubro & 0 & 25,8 & 54 & 2 & 25,3 & 72 & 0 & 27,4 & 62 \\
\hline Novembro & $\mathbf{0}$ & 26,6 & 52 & 9 & 27,3 & 56 & 22 & 28,6 & 54 \\
\hline Dezembro & 7 & 27,5 & 56 & 8 & 28,2 & 54 & 42 & 28,3 & 56 \\
\hline Total/Média & 807 & 25,2 & 70 & 1.103 & 25,3 & 75 & 722 & 25,1 & 68 \\
\hline
\end{tabular}


e 2009/2010. A cobertura morta constou de uma camada de $5 \mathrm{~cm}$ de espessura, com folhas decíduas da própria cultura e restos vegetais do roço da área experimental, colocada na área de projeção da copa das plantas $\left(7 \mathrm{~m}^{2}\right)$, relativa ao diâmetro da copa de $3 \mathrm{~m}$.

Antes da instalação do experimento foram determinados os atributos químicos e físicos do solo nas camadas de 0-20 e de 21-40 cm e do material vegetal utilizado como cobertura morta do solo (Tabela 2 e 3), empregando-se as metodologias contidas em Empresa Brasileira de Pesquisa Agropecuária (2011). O solo da área experimental foi classificado como Neossolo Quartzarênico Distrófico (EMPRESA..., 2006).

Nos períodos de estiagem de setembro de 2008 a fevereiro de 2009 , setembro de 2009 a fevereiro de 2010 e de setembro a dezembro de 2010, o fornecimento de água as plantas foi realizado semanalmente pelo método microaspersão. Essa irrigação foi feita na área de projeção da copa adotando-se os valores unitários de coeficiente de cobertura pela planta (Cs) e coeficiente de cultura $(\mathrm{Kc})$. Semanalmente eram fornecidos $120 \mathrm{~L}$ de água não salina $\left(\mathrm{CEa}=0,58 \mathrm{dS} \mathrm{m}^{-1}\right)$ e razão de adsorção

Tabela 2. Atributos químicos do solo e dos restos culturais, antes da aplicação dos tratamentos, Remígio - PB.

\begin{tabular}{|c|c|c|c|c|}
\hline \multirow{2}{*}{ Atributos } & \multirow{2}{*}{ Unidade } & \multicolumn{2}{|c|}{ Solo } & \multirow{2}{*}{ RC } \\
\hline & & $0-20 \mathrm{~cm}$ & $20-40 \mathrm{~cm}$ & \\
\hline pH & H2O $(1: 2,5)$ & 7,3 & 6,6 & 7,13 \\
\hline MO & $\mathrm{g} \mathrm{kg}^{-1}$ & 8,45 & 4,25 & 380 \\
\hline $\mathbf{P}$ & $\mathrm{mg} \mathrm{dm}^{-3}$ & 58,11 & 33,25 & 235,08 \\
\hline $\mathbf{K}^{+}$ & $\mathrm{mg} \mathrm{dm}^{-3}$ & 105 & 89,5 & 1307,17 \\
\hline $\mathrm{Na}^{+}$ & $\mathrm{cmol}_{\mathrm{c}} \mathrm{dm}^{-3}$ & 0,24 & 0,17 & 3,15 \\
\hline $\mathbf{H}^{++} \mathbf{A l}^{+3}$ & $\mathrm{cmol}_{\mathrm{c}} \mathrm{dm}^{-3}$ & 0,54 & 0,87 & - \\
\hline $\mathbf{A l}^{+3}$ & $\mathrm{cmol}_{\mathrm{c}} \mathrm{dm}^{-3}$ & $\mathbf{0}$ & 0 & - \\
\hline $\mathrm{Ca}^{+2}$ & $\mathrm{cmol}_{\mathrm{c}} \mathrm{dm}^{-3}$ & 2,03 & 1,18 & 1,75 \\
\hline $\mathrm{Mg}^{+2}$ & $\operatorname{cmol}_{c} \mathrm{dm}^{-3}$ & 0,54 & 0,4 & 2,7 \\
\hline SB & $\mathrm{cmol}_{\mathrm{c}} \mathrm{dm}^{-3}$ & 3,01 & 1,97 & - \\
\hline СТC & $\operatorname{cmol}_{c} \mathrm{dm}^{-3}$ & 3,62 & 2,85 & - \\
\hline $\mathbf{V}$ & $\%$ & 83,15 & 71,98 & - \\
\hline
\end{tabular}

MO = Matéria orgânica; $\mathrm{RC}=$ Restos de cultura da propriedade (restos de gramíneas nativas, restos de folhas de outras plantas, folhas e ramos finos da gravioleira).

Tabela 3. Atributos físicos do solo antes da aplicação dos tratamentos nas profundidades 0-20 e 21-40 cm, Remígio - PB.

\begin{tabular}{lcc}
\hline \multicolumn{1}{c}{ Variáveis } & $0-20 \mathrm{~cm}$ & $21-40 \mathrm{~cm}$ \\
\hline Areia grossa $\left(\mathrm{g} \mathrm{kg}^{-1}\right)$ & 915 & 908 \\
Silte $\left(\mathrm{g} \mathrm{kg}^{-1}\right)$ & 55 & 61 \\
Argila $\left(\mathrm{g} \mathrm{kg}^{-1}\right)$ & 30 & 31 \\
Densidade do solo $\left(\mathrm{g} \mathrm{cm}^{-3}\right)$ & 1,43 & 1,42 \\
Densidade de partícula $\left(\mathrm{g} \mathrm{cm}^{-3}\right)$ & 2,72 & 2,73 \\
Porosidade total $\left(\mathrm{m}^{3} \mathrm{~m}^{-3}\right)$ & 0,47 & 0,48 \\
\hline
\end{tabular}

Colunas com letras minúsculas comparam os efeitos das lâminas de irrigação dentro da cobertura morta, letras maiúsculas comparam os efeitos de cada lâmina de irrigação dentro da cobertura morta em cada safra e letras gregas comparam os efeitos da cobertura morta dentro das safras pelo teste F para $\mathrm{p}>0,05$. de sódio $\left[\mathrm{RAS}=3,2\left(\mathrm{mmol} \mathrm{L}^{-1}\right)^{1 / 2}\right.$ na área de projeção da copa das plantas de $7 \mathrm{~m}^{2}$, correspondente a lâmina de irrigação de $17,2 \mathrm{~mm}$. Um microaspersor com vazão de $60 \mathrm{~L} \mathrm{~h}^{-1}$, raio de alcance de $2,5 \mathrm{~m}$, foi instalado na linha a $50 \mathrm{~cm}$ de distância de cada planta com o microaspersor instalado na altura suficiente para molhamento da área de projeção da copa, operando na pressão de serviço de 0,2 $\mathrm{MPa}$.

Antes de iniciar o experimento, no início do período chuvoso, março de 2008, cada planta foi adubada em cobertura com $100 \mathrm{~g}$ de $\mathrm{N}, 100 \mathrm{~g}$ de $\mathrm{P}_{2} \mathrm{O}_{5}$ e $110 \mathrm{~g}$ de $\mathrm{K}_{2} \mathrm{O}$, na forma de ureia (45\%), superfosfato simples $(20 \%)$ e cloreto de potássio $(60 \%)$, respectivamente. No final de julho do mesmo ano, as adubações foram realizadas com $160 \mathrm{~g}$ de $\mathrm{N}, 50 \mathrm{~g}$ de $\mathrm{P}_{2} \mathrm{O}_{5} \mathrm{e}$ $200 \mathrm{~g}$ de $\mathrm{K}_{2} \mathrm{O}$, conforme Pinto et al. (2001). Esses valores foram repetidos no início e final dos períodos chuvosos de 2009 e 2010, respectivamente. Pelo baixo teor de matéria orgânica do solo foram fornecidos em junho de cada ano $20 \mathrm{~L}$ de esterco bovino de relação $\mathrm{C}: \mathrm{N}=18: 1$, distribuídos na área de projeção da copa de cada planta. As colheitas corresponderam aos períodos de outubro/2008 a março/2009 (safra 2008/2009) e de setembro/2009 a março/2010 e setembro a dezembro/2010 (safra 2009/2010), coletando-se os frutos que apresentavam maturidade fisiológica reconhecida pela maior separação entre as terminações estilares e da perda de consistência das respectivas estruturas.

Os dados foram submetidos à análise de variância de medidas repetidas no tempo (safra), considerando-se a estrutura de covariância autorregressiva (AR1). As médias de número e massa média de frutos, produção por planta e produtividade foram comparadas pelo teste F, empregando o PROC MIXED do SAS, para calcular a REML (restricted maximum likelyhood), software SAS/STAT versão 9.3 (STATISTICAL..., 2011).

\section{Resultados e Discussão}

$\mathrm{O}$ número de frutos colhidos por planta foi influenciado pela interação irrigação, cobertura morta do solo e safras (Figura 1). No solo sem e com irrigação a produção das plantas sem cobertura morta na safra 2008/2009 aumentou de 14 para 54 e com cobertura morta de 19 para 60 proporcionando um

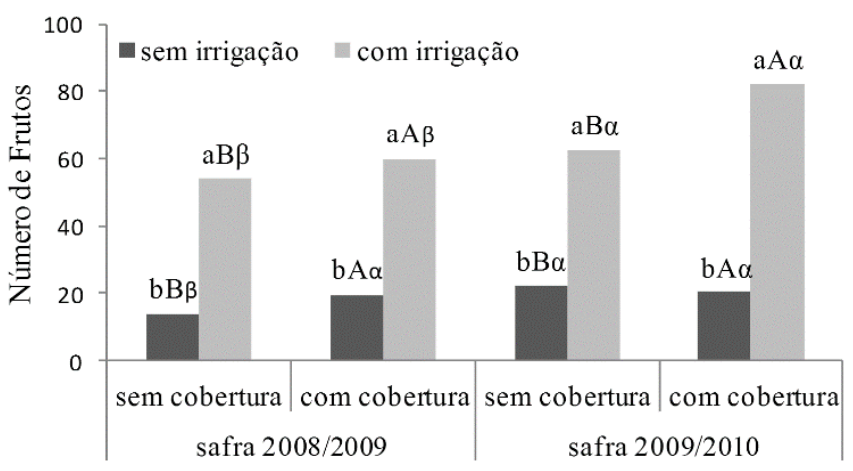

Figura 1. Número de frutos em plantas sem () e com () irrigação, no solo sem e com cobertura morta e nas safras de 2008/2009 e 2009/2010, Remígio - PB. Colunas com letras minúsculas distintas diferem entre si pelo teste $\mathrm{F}$ para $p>0,01 ; p>0,05$ e p > 0,01, respectivamente em função da irrigação (a), cobertura (b) e safras (c). 
incremento de $285 \%$ e $215 \%$ entre os tratamentos. Nas mesmas condições, na safra seguinte $(2009 / 2010)$, os aumentos foram elevados de 22 para 62 e de 20 para 82, respectivamente, com incrementos de $181 \%$ e $310 \%$. Pela comparação dos dados, verifica-se que apesar dos menores valores dos frutos das plantas sem cobertura em ambas as safras, o uso da irrigação promoveu aumentos expressivos na produção da gravioleira. A umidade no solo favorecida pela irrigação, apesar da baixa lâmina de irrigação aplicada, contribuiu para a solubilização, transporte e absorção dos nutrientes pelas plantas, resultando em melhores condições para a produção de frutos pela gravioleira. Resultados semelhantes foram observados por Sousa et al. (2005) ao avaliarem a eficiência do uso da água pelo maracujazeiro amarelo em quatro níveis de irrigação no Estado do Ceará.

Ao avaliar os efeitos da cobertura morta nas diferentes safras (Figura 1) percebe-se que, em ambas, o número de frutos foi significativamente maior nas plantas dos tratamentos com cobertura morta do solo, mas com destaque para as plantas do solo com cobertura morta sob irrigação, com incremento de $36 \%$ na segunda safra. A cobertura morta do solo induziu a maior produção de frutos por manter o solo mais úmido e com menor temperatura, proporcionando maior produção das plantas. Comportamento semelhante foi registrado por Sediyama et al. (2011) em plantas de beterraba sob adubação orgânica e cobertura morta do solo. Para Freire et al. (2014), a cobertura morta reduz as altas taxas de evapotranspiração do maracujazeiro amarelo nas épocas mais quentes do ano e estimula a produção de clorofila e trocas gasosas das plantas, resultando em maior produção.

A massa média de frutos foi influenciada significativamente pelo efeito isolado dos fatores avaliados (Figura 2). As plantas irrigadas semanalmente, mesmo sob irrigação de salvação, produziram frutos com massa média 33,5\% superior aos frutos das plantas não irrigadas (Figura 2a). Essa situação assemelha-se à verificada por Gondim et al. (2009) em que a irrigação com lâminas de 5,3;7,9;10,5;13,1 mm aplicados diariamente elevou significantemente a massa média dos frutos de maracujazeiro amarelo. Essa situação evidencia, que a deficiência de água, além de comprometer a frutificação, reduz a massa média dos frutos produzidos pela gravioleira e pode inviabilizar a produção de frutíferas como registrado por Freire et al. (2010) no maracujazeiro amarelo.

A cobertura morta do solo, embora em nível menos expressivo que a irrigação, também estimulou a produção de frutos com maior massa, promovendo incremento de $23,4 \%$ na massa dos frutos das plantas cultivadas com cobertura morta em relação às do solo descoberto (Figura $2 b$ ). De forma semelhante à superioridade observada para o número de frutos, a ação positiva da cobertura morta ao solo proporcionou maior massa média de fruto da gravioleira, como apresentado também por Karasawa et al. (2008) em melancieira, Factor et al. (2009) em tomateiro, Sediyama et al. (2011) em beterraba e Teófilo et al. (2012) em meloeiro.

Comparativamente, constata-se que a massa média dos frutos foi elevada significativamente da primeira para a segunda safra, com superioridade de $27,1 \%$ da safra 2009/2010 em relação à 2008/2009 (Figura 2c). Essa superioridade é resposta da maior pluviosidade de $1103 \mathrm{~mm}$ registrados em
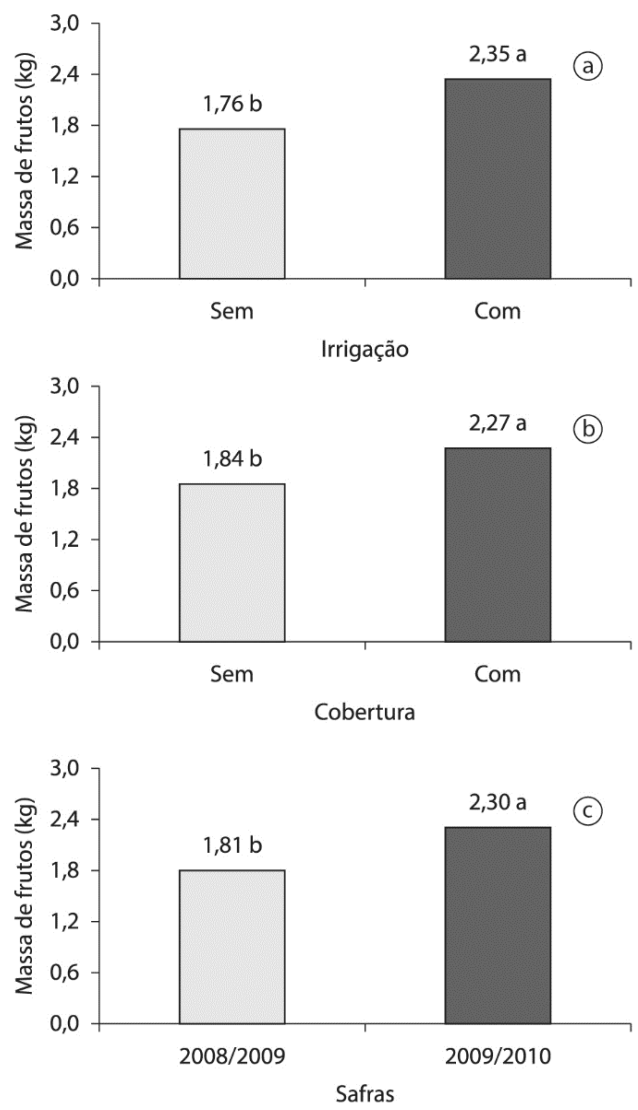

Figura 2. Massa Média de frutos colhidos de plantas sem e com irrigação de salvação (a), no solo sem e com cobertura morta (b) e (c) nas safras 2008/2009 e 2009/2010, Remígio - PB. Colunas com letras minúsculas comparam os efeitos das lâminas de irrigação dentro da cobertura morta, letras maiúsculas comparam os efeitos de cada lâmina de irrigação dentro da cobertura morta em cada safra e letras gregas comparam os efeitos da cobertura morta dentro das safras pelo teste $\mathrm{F}$ para $\mathrm{p}>0,01$.

2009 (Tabela 1) contribuindo para maior solubilização dos fertilizantes aplicados, adequada absorção dos nutrientes resultando em nutrição mais equilibrada das plantas. Apesar da maior massa média de $2,35 \mathrm{~kg}_{\text {fruto }}{ }^{-1}$ ser obtida nas plantas sob irrigação de salvação o valor é $26,8 \%$ inferior aos $3,21 \mathrm{~kg}$ colhidos por Sacramento et al. (2003) em gravioleira 'Morada' não irrigada em Ilhéus-BA. Esses resultados expressam que a lâmina de água de $17,2 \mathrm{~mm}$ correspondente a $120 \mathrm{~L} \mathrm{planta}^{-1}$, fornecida semanalmente, é baixa para uma cultura com o porte da gravioleira, que, em produção, exige, em média, $130 \mathrm{~L} \mathrm{planta}^{-1} \mathrm{dia}^{-1}$ (FONTENELE et al., 2013). Por outro lado, ao se relacionar o valor $2,35 \mathrm{com} 1,76 \mathrm{~kg}$ fruto $^{-1}$ constata-se que a irrigação de salvação elevou a massa média dos frutos em mais de 33\%, comparadas às plantas sem irrigação (Figura 2a).

A interação irrigação $\times$ cobertura do solo interferiu significativamente na produção individual das plantas entre as safras de 2008/2009 e 2009/2010 (Figura 3). No solo sem e com cobertura morta, a produção das plantas não irrigadas na safra 2008/2009 aumentou de 18,5 $\mathrm{kg}$ planta $^{-1}$ para 35,8 $\mathrm{kg} \mathrm{planta}^{-1}$ e das irrigadas, de $35,8 \mathrm{~kg}$ planta $^{-1}$ para $119,5 \mathrm{~kg}$ planta $^{-1}$. Nas mesmas condições, na safra seguinte (2009/2010), os aumentos foram elevados de $35,4 \mathrm{~kg}_{\text {planta }}{ }^{-1}$ para $43,8 \mathrm{~kg}_{\text {planta }}{ }^{-1}$ e de $184,4 \mathrm{~kg}_{\text {planta }}{ }^{-1}$ para 194,2 $\mathrm{kg} \mathrm{planta}^{-1}$, respectivamente. 
Pela comparação dos dados, verifica-se que apesar dos menores valores dos frutos das plantas não irrigadas, nas respectivas safras, o uso da cobertura morta promoveu aumentos promissores na produção da gravioleira, apesar da expressiva superioridade das plantas irrigadas.

A partir dos resultados de $184,4 \mathrm{~kg}$ e $194,2 \mathrm{~kg}$ as plantas sob irrigação de salvação no solo sem e com cobertura morta em 2009/2010, comparados aos 35,8 kg e 119,5 kg nos mesmos tratamentos em 2008/2009, constata-se que a irrigação, mesmo sendo insuficiente, as exigências da cultura supera os efeitos da cobertura morta no solo na produção da gravioleira.

A partir das produções individuais de $18,5 \mathrm{~kg}$ e $35,8 \mathrm{~kg}$; $35,4 \mathrm{~kg}$ e $184,4 \mathrm{~kg}$ planta $^{-1}$ nas plantas sem e com irrigação de salvação, respectivamente, na condição sem cobertura do solo. Enquanto com adição de cobertura do solo foram obtidos $35,8 \mathrm{~kg}$ e $119,5 \mathrm{~kg} ; 43,8 \mathrm{~kg}$ e $194,2 \mathrm{~kg}$ planta $^{-1}$ nas plantas sem e com irrigação de salvação, respectivamente, constatam-se expressivas superioridades promovidas pela irrigação em qualquer das safras, mas com marcante supremacia na safra de 2009/2010.

O comportamento estatístico das produções individuais por planta, indicadas na Figura 3, são transferidas para a produtividade da cultura (Figura 4). Os incrementos do número de frutos colhidos, massa média de frutos e da produção por

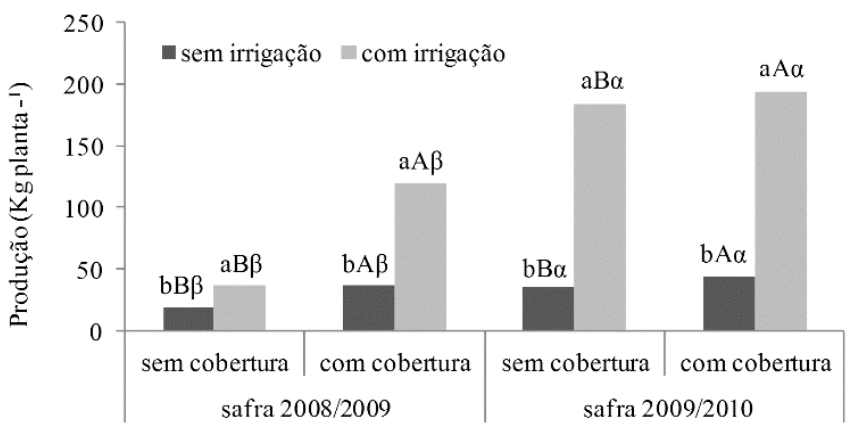

Figura 3. Produção de frutos por planta sem () e com () irrigação, no solo sem e com cobertura morta, nas safras de 2008/2009 e 2009/2010, Remígio - PB. Colunas com letras minúsculas comparam os efeitos das lâminas de irrigação dentro da cobertura morta, letras maiúsculas comparam os efeitos de cada lâmina de irrigação dentro da cobertura morta em cada safra e letras gregas comparam os efeitos da cobertura morta dentro das safras pelo teste F para $\mathrm{p}>0,01$.

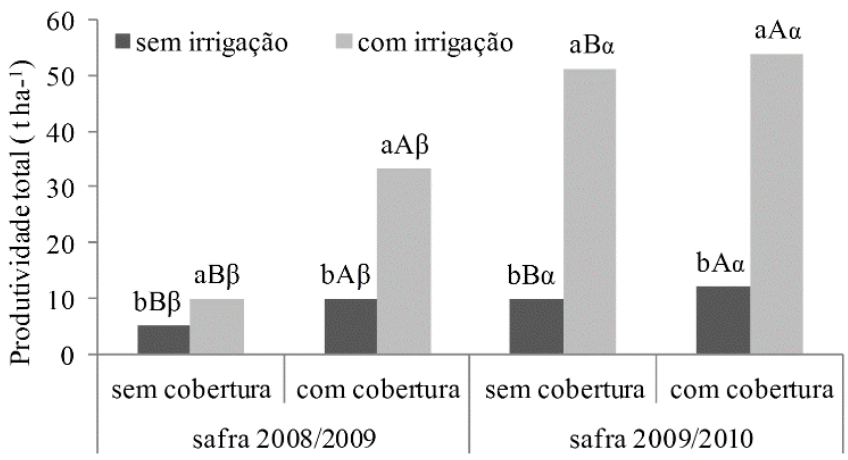

Figura 4. Produtividade de frutos de plantas sem () e com () irrigação, no solo sem e com cobertura morta, nas safras de 2008/2009 e 2009/2010, Remígio - PB. planta resultaram em aumentos de produtividade entre as plantas sem irrigação de 5,1 para 9,9 tha $\mathrm{th}^{-1}$ e de 9,8 para $12,1 \mathrm{t} \mathrm{ha} \mathrm{a}^{-1}$ no solo sem e com cobertura morta, respectivamente nas safras de 2008/2009 e 2009/2010. Nas respectivas safras a irrigação de salvação, mesmo sendo insuficiente, segundo a estimativa dos autores Fontenele et al. (2013), elevou o rendimento das plantas de 9,9 $\mathrm{t} \mathrm{ha}^{-1}$ para 33,2 $\mathrm{tha}^{-1}$ e de 51,2 $\mathrm{t} \mathrm{ha}^{-1}$ para 53,4 $\mathrm{tha}^{-1}$ nas respectivas safras.

Em uma avaliação global, os rendimentos da gravioleira não irrigada de $5,1 \mathrm{t} \mathrm{ha}^{-1}$ para $9,9 \mathrm{tha}^{-1}$ e de $9,8 \mathrm{tha}^{-1}$ para $12,1 \mathrm{t} \mathrm{ha} \mathrm{h}^{-1}$ se inserem na amplitude de $10 \mathrm{t} \mathrm{ha}^{-1}$ a $12 \mathrm{t} \mathrm{ha}^{-1}$ apresentada por Ramos, Pinto e Rodrigues (2001), em cultivo não irrigado, mas, as produtividades das plantas sob irrigação de salvação com valores de 9,9 $\mathrm{t} \mathrm{ha}^{-1}$ para 33,2 $\mathrm{t} \mathrm{ha}^{-1}$ e de 51,2 $\mathrm{t} \mathrm{ha}^{-1}$ para $53,4 \mathrm{tha}^{-1}$ superam expressivamente as apresentadas por esses autores. Esses resultados são superiores, ainda, à variação de rendimento de $3 \mathrm{t} \mathrm{ha}^{-1}$ a $20 \mathrm{t} \mathrm{ha}^{-1}$ para diversas variedades de graviola e o potencial produtivo da gravioleira "Morada" de até 30 t ha-1, apresentada por São José et al. (2000).

Os resultados obtidos na produção por planta evidenciam a ação positiva da cobertura morta no aumento da produtividade da gravioleira, mas, com expressiva superioridade da irrigação de salvação. A supremacia constatada entre as safras pode ser atribuída também à elevada pluviosidade de $1.103 \mathrm{~mm}$ no ano de 2009 em relação aos 807 e 722 mm registrados em 2008 e 2010 (Tabela 1), contribuindo para maiores números de frutos colhidos, massa de frutos e produção por planta na safra 2009/2010. Nesse sentido, ao adicionar as lâminas aplicadas, nos períodos de irrigação de setembro a dezembro de 2008 $(275,2 \mathrm{~mm})$, de janeiro a fevereiro e de setembro a dezembro de 2009 (412,8 mm), bem como de janeiro a fevereiro e de setembro a dezembro de 2010 (412,8 mm), às pluviosidades nos mesmos períodos, constatam-se valores totais de 319,2; 510,8 e 496,8 mm nos referidos períodos e anos de cultivo. Ao considerar que nos mesmos períodos as exigências hídricas da gravioleira, conforme Fontenele et al. (2013), seriam de 444, 654 e $654 \mathrm{~mm}$ nos referidos anos esses valores caracterizam deficiências de 28,1;21,9 e 24,3\%, em cada respectivo ano de cultivo e possivelmente os efeitos negativos dessas deficiências tenham sido reduzidos pelas pluviosidades durante o período chuvoso de cada ano. Adicionalmente, a pluviosidade promove a decomposição do material vegetal utilizado na cobertura morta do solo e, consequentemente, contribui para a melhoria das qualidades física, química e biológica do solo ao longo do tempo (SILVA et al., 2007; SEDIYAMA et al., 2011), resultando em maior produtividade da cultura.

\section{Conclusões}

A irrigação de salvação semanal foi mais eficiente que a cobertura morta do solo, nos componentes de produção da gravioleira;

A cobertura morta do solo promove aumento nos componentes da produção da gravioleira em relação ao plantio tradicional, sem cobertura morta;

A aplicação da irrigação de salvação juntamente com a cobertura morta pode refletir em bons resultados para a produção. 


\section{Referências}

EMPRESA BRASILEIRA DE PESQUISA AGROPECUÁRIA - EMBRAPA. Centro Nacional de Pesquisa de Solos. Sistema brasileiro de classificação de solos. Rio de Janeiro: Embrapa SPI, 2006. 312 p.

EMPRESA BRASILEIRA DE PESQUISA AGROPECUÁRIA EMBRAPA. Serviço Nacional de Pesquisa de Solos. Manual de métodos de análises de solos. 3. ed. Rio de Janeiro: Embrapa Solos, 2011. $230 \mathrm{p}$.

FACTOR, T. L. et al. Produtividade e qualidade de tomate em função da cobertura do solo e planta com agrotêxtil. Horticultura Brasileira, Brasília, v. 27, n. 2, p. 606-612, 2009.

FERREIRA, T. T. S.; RODRIGUES, D. N. B.; GOMES FILHO, R. R. Demanda hídrica de fruteiras utilizando coeficiente de redução da evapotranspiração adequado a região do Baixo Jaguaribe no Ceará. Revista Brasileira de Agricultura Irrigada, Fortaleza, v. 4, n. 4, p. 217-225, 2010. http://dx.doi.org/10.7127/rbai.v4n400029.

FONTENELE, A. J. P. B. et al. Demanda hídrica de fruteiras utilizando coeficiente de redução adequado ao perímetro irrigado Baixo Acaraú-CE. Revista Brasileira de Agricultura Irrigada, Fortaleza, v. 7, n. 2, p. 136-145, 2013. http://dx.doi.org/10.7127/ rbai.v7n200013.

FREIRE, J. L. O. et al. Atributos qualitativos do maracujá amarelo produzido com água salina, biofertilizante e cobertura morta no solo. Revista Brasileira de Ciências Agrárias, Pernambuco, v. 4, n. 4, p. 102-110, 2010. http://dx.doi.org/10.5039/agraria.v5i1a674.

FREIRE, J. L. O. et al. Rendimento quântico e trocas gasosas em maracujazeiro amarelo sob salinidade hídrica, biofertilização e cobertura morta. Revista Ciência Agronômica, Fortaleza, v. 45, n. 1, p. 82-91, 2014. http://dx.doi.org/10.1590/S1806-66902014000100011.

GARCÍA-SOTO, A. et al. Propagación y fertilización del cultivo del guanábano. II: características químicas de frutos. Revista de la Facultad de Agronomía, Maracaibo, Venezuela, v. 29, n. 1, p. 20-26, 2012.

GONDIM, S. C. et al. Produção e composição foliar do maracujazeiro amarelo sob lâminas de irrigação. Revista Caatinga, Mossoró, v. 22, n. 4, p. 100-107, 2009.

KARASAWA, M. et al. Características produtivas de melancias "Icebox" submetidos a diferentes coberturas do solo. Horticultura Brasileira, Brasília, v. 26, n. 2, p. 5711-5715, 2008.
LIMA NETO, A. J. et al. Biofertilizante bovino, cobertura morta e revestimento lateral dos sulcos na produção de pimentão. Revista Caatinga, Mossoró, v. 26, n. 3, p. 1-8, 2013.

PAREEK, S. et al. Postharvest physiology and technology of Annona fruits. Food Research International, Canadá, v. 44, n. 7, p. 1741-1751, 2011. http://dx.doi.org/10.1016/j.foodres.2011.02.016.

PINTO, A. C. Q. et al. Tratos culturais. In: OLIVEIRA, M. A. S. (Ed.). Graviola: produção, aspectos técnicos. Brasília: Embrapa Informação Tecnológica, 2001. p. 26-33, (Frutas do Brasil, 15).

RAMOS, V. H. V.; PINTO, A. C. Q.; RODRIGUES, A. A. Colheita e pós-colheita. In: OLIVEIRA, M. A. S. (Ed.). Graviola: produção, aspectos técnicos. Brasília: Embrapa Informação Tecnológica, 2001 p. 52-57, (Frutas do Brasil, 15).

SACRAMENTO, C. D. et al. Caracterização física e química de frutos de três tipos de gravioleira (Annona muricata L.). Revista Brasileira de Fruticultura, Jaboticabal, v. 25, n. 2, p. 329-331, 2003.

SÃO JOSÉ, A. R. et al. Cultivo da graviola. Vitoria da Conquista: UESB, 2000. 27 p.

STATISTICAL ANALYSIS SYSTEM - SAS. SAS/STAT 9.3 User's Guide. Cary, NC: SAS Institute Inc., 2011.

SEDIYAMA, M. A. N. et al. Produtividade e exportação de nutrientes em beterraba cultivada com cobertura morta e adubação orgânica. Revista Brasileira de Engenharia Agrícola e Ambiental, Campina Grande, v. 15, n. 9, p. 883-889, 2011.

SILVA, E. B.; FARNEZI, M. M. M. Limitações nutricionais para o crescimento de mudas de graviola em casa de vegetação em Latossolo Vermelho Distrófico do norte de Minas Gerais. Bioscience Journal, Uberlândia, v. 25, n. 6, p. 52-58, 2009.

SILVA, J. C. G. et al. A Influência da cobertura morta sobre características físicas e químicas de frutos da pinha (Annona squamosa L.). Revista Brasileira de Fruticultura, Jaboticabal, v. 29, n. 2, p. 287-291, 2007. http://dx.doi.org/10.1590/S0100-29452007000200019.

SOUSA, V. F. et al. Eficiência do uso da água pelo maracujazeiro amarelo sob diferentes níveis de irrigação e doses de potássio. Revista Brasileira de Engenharia Agrícola e Ambiental, Campina Grande, v. 9, n. 3, p. 302-306, 2005. http://dx.doi.org/10.1590/ S1415-43662005000300002.

TEÓFILO, T. M. S. et al. Eficiência no uso da água e interferência de plantas daninhas no meloeiro cultivado nos sistemas de plantio direto e convencional. Planta Daninha, Viçosa, v. 30, n. 3, p. 547-556, 2012. http://dx.doi.org/10.1590/S0100-83582012000300010. 